\title{
Relationship between Medical Professionals and Patients: Exploring the Role of Nonviolent Communication in Enhancing Engagement
}

\author{
Shazaf Masood Sidhu \\ The Peace Gong Global Coordinator, (Practicing Doctor at Aga Khan University Hospital, Karachi, Pakistan) \\ Corresponding author: shazafmasood@gmail.com
}

Received: 12 Mar., 2020

Revised: 19 Apr, 2020

Accepted: 29 May, 2020

\begin{abstract}
There is an intricate relationship between medical professionals and patients. Continuing with their Hippocratic Oath, doctors are expected to adhere to the "utmost respect for human life from its beginning". In the backdrop of increasing stress and commercial interests, it is possible that the relationship between the medical professionals and patients become mechanical guided by monetary interests. Such a relationship is not good either for the medical professionals or for the patients. In distress due to health reasons, patients trust their doctors to heal them. For evolution of a genuine relationship, it is important that doctors not only focus on medical healing but also provide them the succor and mental satisfaction that they will get better. In this context, the role of nonviolent communication in being the fulcrum of the communication process between medical professionals and doctors is significant. This chapter will look the role of nonviolent communication in how nonviolent communication enhances engagement between the two.
\end{abstract}

Keywords: nonviolent communication, doctor-patient relationship, empathetic connections

Within every patient there resides a doctor, and we as physicians are at our best when we put our patients with the doctor inside themselves.

- Albert Schweitzer

Circa 2018: A conversation with a cancer patient who was fighting with her stage III colorectal carcinoma. The patient was full of negativity and constantly complaining that the multiple chemo sessions that she was undergoing was not improving her conditions. She complained that the chemo sessions were not successfully done by the medical professions. It was then the author had an almost two-hour long conversation with the patient ranging from her life, her twins, the beautiful moments that she had with her children, her friends and relatives. After all the author was her doctor. The aim was to empathize with the patient and take her to a zone of positive feelings where she could start appreciating the good things around.

Post her chemo the author once again met the patient and surprisingly enough she was a different

How to cite this article: Sidhu, S.M. (2020). Relationship between Medical Professionals and Patients: Exploring the Role of Nonviolent Communication in Enhancing Engagement. Int. J. Peace, Edu. and Deve., 8(01): 49-54.

Source of Support: None; Conflict of Interest: None 
person. This time the patient was smiling and she had the courage to fight in all true means, she actually looked a lot more positive about her metastasis. The patient felt the chemo was successful this gave her a new hope of survival. The author and the patient were both 'teary-eyed'; she held the author's hand and thanked her for the deep conversation, for hearing her out and for giving her faith that things will get better.

This deep conversation with the patient motivated the author to explore the centrality of nonviolent communication in not only enhancing the trust between medical professionals and patients but also play a key role in taking patients to zones of positivity. Patients, mainly those, who are suffering from debilitating diseases like cancer find themselves in low life conditions. Experience of handling such patients suggests that many of them get themselves engulfed in negative frames; most of them feel that nothing good can happen to them anymore and they would be consigned to a dark abyss for the rest of their lives. It is where the role of medical professionals becomes critical and their ingenuity in intertwining professionalism with empathy and compassion comes to the fore. This is what the author feels is the art of medicine which entails using all available knowledge and skills with a deep sense of humanism. For a doctor, the patient who is sitting in front is the only person who matters in that moment. It is her/his ingenuity to make the patient feel that the doctor is totally committed to her/his well-being.

The intricate relationship between medical professionals and patients comes to the fore more than ever before in times of pandemics like the one the world is witnessing presently due to Covid-19. Medical professionals around the world are doing exemplary work risking their own lives to save precious lives. There are large number of stories which reflects on how communities in different parts of the world are commending the role of the medical professionals. But there are also stories where people are seen attacking medical professionals. This takes us to the core issue of the relationship between medical professionals and patients. There are contentions and contestations of the changing nature of this relationship. Whileon the one hand critics suggests that major strides towards commercialization of the health sector and the infusion of vested interests have taken the relationship to a purely money-making business, there are others who still vouch for the sanctity of the relationship. It is a never-ending debate. While it may be argued that black sheep exist in every profession, pandemics like the coronavirus challenges the medical community to give its very best to work for the survival of fellow human beings.

Also, the pandemic gives us the frame to revisit the relationship between medical professionals and patients; for the medical community across the world it is a unique opportunity. The pandemic offers a window to discuss and find innovative ways to develop a humanistic relationship. The chapter is an attempt to put together such an innovation.

Meanwhile several studies have shown that emotions and empathy matter in better patientmedical professionals' relationship. For instance, Boodman (2015) notes, "Studies have linked empathy to greater patient satisfaction, better outcomes, decreased physician burnout, and a lower risk of malpractice suits and errors." Patientcentered care and relationship-care are important goals of medical professionals. It is a philosophy which takes the patient-medical professionals relationship governed by specific roles to a deeper engagement between human beings. Here the emphasis is on people and their specific roles come later.

If the objectives of patient-centered care and relationship-care are to be achieved then the communication between the medical professionals and patients' needs to have greater depth than just the mechanistic form of communication which is practiced in many instances. As can be gauged from the authors experience of deep communication with her patient which resulted in the patient experiencing a feel-good environment and moving towards a zone of positivity, the manner in which a medical professional- be it a doctor or a nurse communicates with a patient makes a lot of difference on how the patients feels. 
Travaline et al. (2005) underscores, "Patient-physician communication is an integral part of clinical practice. When done well, such communication produces a therapeutic effect for the patient, as has been validated in controlled studies." They further note:

The manner in which a physician communicates information to a patient is as important as the information being communicated. Patients who understand their doctors are more likely to acknowledge health problems, understand their treatment options, modify their behavior accordingly, and follow their medication schedules. In fact, research has shown that effective patientphysician communication can improve a patient's health as quantifiably as many drugs-perhaps providing a partial explanation for the powerful placebo effect seen in clinical trials.

Meanwhile Fong Ha et al. (2010) argue, "A doctor's communication and interpersonal skills encompass the ability to gather information in order to facilitate accurate diagnosis, counsel appropriately, give therapeutic instructions, and establish caring relationships with patients. These are the core clinical skills in the practice of medicine, with the ultimate goal of achieving the best outcome and patient satisfaction, which are essential for the effective delivery of health care."

Fong Ha et al. further argue that the overarching objective of the doctor-patient communication is to improve the health of the patient and medical care. They talk of surveys which suggest that patients want better communication with doctors. The bottleneck in the communication process comes to the fore when studies indicate that patients express dissatisfaction with how their doctors interact with them even though the doctors believe that their communication efforts were excellent.

Travaline's perspectives, Fong Ha's arguments and the authors own experience as a doctor suggest on the need for delve more closely on the oft neglected area in the medical profession- the nature of communication architecture governing the relationship between medical professionals and patients. This chapter through the author's own understanding of the intricate relationship between medical professionals and patients will explore the centrality of nonviolent communication as a strategy which could help in achieving the objectives patient-centered care and relationshipcare. The aim would be to argue on how integration of nonviolent communication in the practice of medical professionals could be an innovative attempt to provide a humanistic approach to medical professionals-patient relationship.

\section{What is Nonviolent Communication and why it matters in the Medical Profession}

A comprehensive understanding of what is nonviolent communication emanates from Natwar Thakkar (Kundu, 2018). While he argues on the need of individuals to critically understand the art and science of nonviolence in our daily lives, he explains how nonviolent communication helps in strengthening of relationships. Thakkar notes:

To me nonviolent communication literacy would mean how our communication efforts should be nonviolent; how our ability and capacity to communicate not only with ourselves but with our family and society be nonviolent in all aspects and overall how the entire process of communication whether between individuals, groups, communities and the world at large should be nonviolent in nature.

Thakkar further explains how nonviolent communication leads to emotional bridge-building, empathetic connections, enhanced expression of compassion and gratitude. He points out that when we are using nonviolent communication, we are essentially seeing the humanness on the other person, we are avoiding stereotype. He underlines the importance of deep and active listening as a significant element of nonviolent communication. Nonviolent communication essentially means we are practicing respect for others, developing greater understanding of the needs of others and being able to appreciate the positives.

Meanwhile Rosenberg (2005) note that nonviolent communication is an integration of thought, language and communication. According to him, the primary purpose of nonviolent communication 
is to connect with other people in a way that enables giving to take place: compassionate giving. He further says, "It's compassionate in that our giving comes willingly from the heart. We are giving service to others and ourselves- not out of duty or obligation, not out of fear of punishment or hope for a reward, not out of guild or shame, but for what I consider part of our nature."

Further, Myra Walden (https://www.sgi.org/content/ files/resources/sgi-quarterly-magazine/1104_64. pdf; Soka Gakai International), explains on the importance of nonviolent communication as she points out, "Many of us have been brought up in environments where competition, judgment, demands and criticism are the communicative norm; at best these habitual ways of thinking and speaking hinder communication and create misunderstanding and frustration in others and ourselves. Still worse, they cause anger and pain and may even lead to violence. Even with the best intentions, we can generate needless conflict. The system of nonviolent communication... begins by assuming we are all compassionate by nature and those violent strategies, whether verbal or physical, are learned behaviours, supported by the prevailing culture. Nonviolent communication helps people learn how to communicate effectively with each other so that their lives and relationships are transformed."

Here it would be pertinent to point out the five pillars of nonviolent communication: respect, understanding, acceptance, appreciation and compassion. So, for medical professionals it is imperative to practice deep respect not only for each other but most importantly for their patients. In a highly commercialized world, medical professionals sometime tend to see their patients more as an object which helps garnering money rather than reach out to them with deep respect. When the professionals make deep respect as part of their habit, it will help them to understand the concerns of their patients. Patients visiting doctors are more than often suffer from low-life condition and may come up with wide ranging concerns. Doctors need to respect these concerns. When they accept the views of the patients with a true sense of humanism, the patients are likely to be more confident of their doctor and would be willing to share greater details of their concern. Nonviolent Communication has thus helped the doctor to build bridge with the patient who now is more trustful of the medical professional.

Amidst daily encounter with life and death, a large number of medical professionals start becoming negative in their outlook. Positive appreciation is a critical element to be imbibed so that doctors can help infuse positive energy amongst their patients. When doctors have the ability to appreciate the good and positive things around them, they can actually channelize these energies to their patients so that it can help them in their low-life conditions.

Finally, the fifth pillar, compassion is extremely crucial in the relationship between medical professionals and patients. If medical professionals do not show compassion to their patients, they are likely to be thrown further down in their life conditions. Compassion helps in providing them succour and plays the role of a catalyst by taking them to a zone of hope that there is a better life ahead.

On the basis of the insights provided by Thakkar (Kundu, 2018), Rosenberg and Walden, it would be apt to look at the different elements of nonviolent communication and its importance in enhancing the relationships between medical professionals and patients. The points discussed are mainly from the point of the view of medical professionals and are based on the author's own experiences.

As Thakkar notes that nonviolent communication entails complete lack of violence in speech, action and thoughts, it is imperative that medical professionals abstain from using language which further accentuates the condition of the patient. Many times, working under pressure, doctors tend to become aggressive in the language they use and even in their body language. This can have unnerving effect on the patient. Awareness of one's body language is critical and it determines of whether the patient is feeling comfortable. Regular use of nonviolent communication will help medical professionals handle difficult situations and yet not be aggressive in their speech and action. 
Medical professionals usually get entrapped in stereotypes and moralistic judgements. Doctors are required to handle patients from diverse background and many a times they tend to stereotype patients coming from a particular group or community. Also, they tend to, in many instances make moralistic judgements on how the patient behaves. For a humanistic relationship, avoidance of stereotypes and moralistic judgement is crucial and by using strategies of nonviolent communication one can learn to avoid such situations.

According to Thakkar, nonviolent communication entails the practitioner to practice active and deep listening. Many times we are not ready to listen to the others. For a doctor who has a large number of patients to attend to may not find hours to listen to a single patient. Possibly, s/he may get not more than 15-20 minutes and in critical cases possibly 30 minutes. Unless, s/he practices the art of active and deep listening, s/he may not be able to gauge the real difficulties of the patient. Also, active and deep listening helps a doctor to explain the situation to the patient and encourage them to be part of the decision-making process for the treatment. Through this the doctor is actually respecting the autonomy of the patient.

By practicing nonviolent communication one can develop empathetic connections. As noted by Boodman (2015) 'empathy training is naturally self-rewarding' as it is likely to give doctors the love back. Empathy is central to trust building and a patient who trusts his/her doctor is more likely to follow the doctor's advice for treatment. Another important function of empathy is to help patient counteract the emotional irrationality they sometimes tend to experience. As the patient realizes the empathetic connection with the doctor, it is likely that $\mathrm{s} / \mathrm{he}$ becomes aware of the irrationality of her/his feelings. This will help the patient to adopt a different perspective which is more in tune of what the doctor is suggesting.

Experience suggests that many times a patient becomes an irritant, difficult to handle. S/he may start criticizing and may show impatience. It is a genuine fact as all wants to get well fast. But if the medical professionals also get entrapped into such situations, they will not be able to perform. Here the practice of nonviolent communication, wherein they make genuine attempts to connect to the needs of their patients comes to their aid.

As a doctor, the author feels the profession gives immense opportunities to serve humankind. Medical professionals have enormous potential to express thanks to every patient and every situation during the course of the day where they learn new things and are required to serve someone. Expression of gratitude is an important element of nonviolent communication. " Here one is reminded of this famous quote of Albert Schweitzer who said, "At times, our own light goes out and is rekindled by a spark from another person. Each of us has cause to think with deep gratitude of those who have lighted the flame within us."

\section{CONCLUSION}

Thakkar (Kundu, 2018) points out, "I believe when we are trying to promote nonviolent communication literacy, we are trying to facilitate relationships based on truthfulness, honesty, genuineness and empathy. Nonviolent communication also entails the elements of gratitude and forgiveness."

At a time when the whole world is reeling under the effect of the Coronavirus, it is important to harness the power of nonviolent communication to develop relationships based on the time-tested values of truthfulness, honesty, genuineness and compassion. It is in this context that nonviolent communication offers a beautiful canvas to medical professionals across the world to practice in right earnest so as to develop a humanistic relationship with their patients.

People are forced to visit their doctors because of the health problem they face. It is not a 'merrygo-around' atmosphere in a hospital or clinic where different people come with different kind of ailments. It may vary from a simple flu to lifethreatening diseases like cancer. Notwithstanding, the behavior of some patients or their kith and kin, it is imperative of the medical professionals to contribute their very best to make their hospitals 
or clinics sites of well-being and deep satisfaction. These should be sites where patients genuinely feel that the doctors are concerned about them and their problems are taken care in the best possible ways. Realization of such an atmosphere requires a twin approach- the medical approach and the communication approach. It is where the importance of nonviolent communication needs to be underlined.

To conclude, it would be apt to quote W.H. Auden:

"A doctor, like anyone else who has to deal with human beings, each of them unique, cannot be a scientist; he is either, like the surgeon, a craftsman, or, like the physician and the psychologist, an artist. This means that in order to be a good doctor a man must also have a good character, that is to say, whatever weaknesses and foibles he may have, and he must love his fellow human beings in the concrete and desire their good before his own."

\section{REFERENCES}

Boodman and Sandra, G. 2015. How to Teach Doctors Empathy; The Atlantic; https://www.theatlantic. com/health/archive/2015/03/how-to-teach-doctorsempathy/387784/

Fong Ha, Jennifer; Surg, Anat Dip and Longneckar, Nancy 2010. Doctor-Patient Communication: A Review; The Ochsner Journal, 10: 38-43.

Kundu, V. 2018. Nurturing Emotional Bridge Building: A Dialogue with Nagaland's Gandhi; Peaceworks; 8(1): 100-109.

Rosenberg, M. 2005. Speak Peace in a World of Conflict; Puddle Dancer Press; USA.

Travaline, John M; Ruchinskas Robert, D'Alonzo, Gilbert E. 2005. Patient-Physician Communication: Why and How; The Journal of American Osteopathic Association, 105(1). 